\title{
Waterproofing basement apartments: technical insights of a new flood protection solution
}

\author{
D. W. Beddoes ${ }^{1,2} \&$ C. A. Booth ${ }^{1}$ \\ ${ }^{1}$ Construction and Property Research Centre, \\ University of the West of England, UK \\ ${ }^{2}$ DrainAngel Ltd., UK
}

\begin{abstract}
Installing perimeter floor drains is a waterproofing option used inside buildings, which manages water ingress in basements. Newly designed products providing a means to access the inverts of perimeter floor drains and facilitate inspection and maintenance have been designed and are Patent Pending GB1117089.1, GB1102662.2, and GB1102661.4. The new system incorporates pivotally connected fittings with water deflector plates combined with straight lengths of perimeter floor drain. The fittings ensure that secure joints with both axial and invert alignment are maintained throughout, which are essential for movement of water through the level perimeter floor drains and accessibility as recommended by British Standard BS8102: 2009. The patents demonstrate several practical advantages over those of existing designs and systems, which is evidenced by the commercial uptake by Safeguard Europe Ltd. and product installations in hundreds of flood-risk basement apartments in the UK.
\end{abstract}

Keywords: property adaptation, perimeter floor drainage, flood resilience, patent product.

\section{Introduction}

Provision of a building basement can increase housing density without a reduction in habitable space and so enable more homes to be built in a development where building height or footprint is limited [1]. Basements have long been used in commercial buildings for plant rooms, storage space and car parking but in recent decades the arcane construction used in basements has been transformed by modern technology to provide fully acceptable below ground 
accommodation, which is particularly beneficial in urban areas where space is limited [2]. Moreover, energy costs can be saved by the use of a basement as heat loss through basement floors and walls is restricted by the insulating effect of the ground, providing possible energy savings of up to $5.6 \%$ for a semidetached and up to $9.5 \%$ for detached properties [3]. One of the major challenges to be addressed with below ground accommodation is the means for preventing the entry of water and water vapour from the surrounding ground into rooms that are wholly or partly below ground level [4]. England has over 20 million dwellings and some 550,000 of these have some form of basement accommodation and the extra space provided by a basement combined with a general shortage of building land leads to the development of sloping sites and results in around 10,000 new basements being constructed every year in England $[5,6]$. In response to an increase in basement construction, the development of new waterproofing materials, more deep basements in cities and the need to mitigate inherent risks associated with below ground structures, the British Standard has been revised. BS8102:1990 code of practice for protection of structures against water from the ground was revised to produce BS8102:2009 code of practice for protection of below ground structures against water from the ground $[7,8]$.

Three types of waterproofing protection should be initially considered [8], where the choices are: (a) barrier protection (Type-A) relies on a separate waterproofing barrier (applied to the structure), which must be totally free of defects if it is to keep water out as hydrostatic pressure will cause flooding of a basement through the smallest of holes; (b) structurally integral protection (Type-B) is provided by the design and materials incorporated into the structure itself and, as such, usually means a building structure using high quality reinforced concrete. Problems come from day joints and construction joints where 'waterstops' in the form of passive (rubber) or active (hydrophilic) strips can sometimes fail at these joints; or (c) drained protection (Type-C) is installed internally and has a major advantage in that no extra loading is placed on the structure, it is a system of internal water management. Plastic cavity drainage membranes combine with perimeter floor drain systems to collect water ingress and direct it to a sump so that it can be pumped from the building. Type-C protection is cost effective and can be retro-fitted to existing basements or readily used as a remedial solution to basements where other types have failed. The Type-C system is not destructive to the basement structure, can be reversed in conservation work, provide insulation together with sound absorption, whilst ensuring that the basement remains dry. Ease of installation, good value and reparability are further major advantages of Type-C protection.

\section{Preference and problems of basement waterproofing}

As a result of developments in plastic membranes and new efficient sump pumps the commonly preferred choice for basement waterproofing is Type-C protection. However, problems have occurred in the past with blockages in membranes and drainage leading to new recommendations in the revised British 
Standards BS8102: 2009 that all drainage systems and installations must now be able to be tested, incorporate accessibility and be maintainable for the life of the structure. In the past the 'Achilles heel' of Type-C protection has always been accessibility into perimeter drainage systems that were buried within the structure, which often resulted in the removal of whole floors to investigate defects.

New products which provide means to access the inverts of perimeter floor drains and facilitate inspection and maintenance are now commercially available [9]. The designs featured are Patent Pending GB1117089.1, GB1102662.2, and GB1102661.4 [10-12]. Perimeter floor drains are used inside buildings that are subject to water ingress, typically basements and flood situations. In a typical basement construction the perimeter floor drain collects water from Type-C (drained cavity) installations as described in BS8102: 2009. A waterproofing installation to BS8102: 2009 Type-C uses waterproof structures to form a cavity between floor, adjacent wall, and/or ceiling which is then drained into the perimeter floor drain. However, the Type-C system is incapable of accepting any hydrostatic pressure and the collected water must be removed from the system or leaks will occur. The perimeter floor drain is one of the most important parts of the water collection and management system that must function properly to prevent water from entering the basement.

The perimeter floor drain is laid directly onto the level floor of the building at the internal wall to floor join, therefore the invert of the perimeter floor drain has to be laid level on the basement floor. The perimeter floor drain is installed around the perimeter of the basement and a T-piece is incorporated at some point to transfer all the water collected by the perimeter floor drain into a link drain which then leads to a sump/pump unit. The sump/pump unit is typically located within the central floor area having a discharge pipe leading to an outside domestic drain. All water ingress through walls, floor, ceilings, the vulnerable wall to floor join and collected from the waterproofing cavities is transported along the perimeter floor drain to the link drain and then into the sump/pump for removal from the building. Most importantly these perimeter floor drains and link drains have no gradient to move the water as they are laid directly onto a level floor. It is the successful movement of the water along the perimeter floor drain that presents the current problem because if the water is allowed to build up then as the Type-C installation cannot withstand hydrostatic pressure we will get leaks into the internal basement space. Furthermore, if water is allowed to pond within the perimeter floor drain then the standing water leads to recrystallization of salts which have entered as a solution within the water. Blockages can then occur due to the deposition of recrystallized salts, which cause more standing water and more blockages etc.

Water can only move along level perimeter floor drains by hydraulic head due to the gravitational effects on the water. This driving force is very weak and it is therefore essential that the invert of the perimeter floor drain is completely level and has no obstructions. Any minor obstruction or misalignment of a perimeter floor drain invert causes an increase in depth of water upstream of the obstruction which may then exert hydrostatic pressure on the waterproofing 
structure and cause a leak into the occupied basement. As a simple illustration we can consider a perimeter floor drain installed in a basement that is $8 \times 6 \mathrm{~m}$ on plan. The water collected by the perimeter floor drain at the furthest point from the link drain will have to travel at least $14 \mathrm{~m}$ and negotiate at least two elbow bends and a T-piece connection into the link drain when the depth of the perimeter floor drain and all that needs to be filled up in order to cause a leak is only $40 \mathrm{~mm}$ depth of standing water within the drain. This example does not take into account the fact that matters are often much worse as there may be a backfall due to the floor itself not being exactly level across its surface. A floor that is $8 \mathrm{~m}$ in length may well be $25 \mathrm{~mm}$ lower at the point furthest away from the link drain, combine this with a mere $5 \mathrm{~mm}$ invert obstruction at each of the two misaligned bends and the T-piece and we have the perimeter floor drain full of water with a potential leak into the occupied building. In these circumstances, which are unfortunately often found on site, the perimeter floor drain cannot be accessed in order to be flushed out and cleaned and it is not possible to maintain the system as per the requirements of BS8102: 2009.

The perimeter floor drain itself is usually made from plastic and has a smooth invert. Usually it is the elbow bends and T-piece, where inverts become misaligned, that causes problems with obstructions that lead to a leak. As a result of problems with Type-C installations and subsequent leaks all new work involving the use of perimeter floor drains is now subject to revised BS8102: 2009 code of practice for protection of below ground structures against water from the ground. This applies to basement and flood situations where accessibility and repairability must be allowed for in design. For example BS8102: 2009 page 13: shows a cross-sectional view of Type-C (drained) protection that details a perimeter floor drain as a maintainable drainage channel, BS8102: 2009: 10.2.1.2. requirements: where the floor cavity incorporates perimeter floor drain channels, which discharge into sump(s), both the channels and the sumps should be cleaned before, during and after installation of the membrane to allow uninterrupted drainage, BS8102:2009: 10.3.1. requirements: access points that allow routine maintenance of channels and outlets should be incorporated into the design of the waterproofing system, BS8102: 10.3.2. requirements: immediately after the installation of a cavity drain system the perimeter floor drainage channels and sumps should be cleaned out and tested. The servicing requirements for the waterproofing system should be clearly set out in the documentation supplied by the designer to the client, including the need for regular planned maintenance of the drainage and/or pumping systems not less than once a year.

In order to have perimeter floor drains that function correctly and also satisfy the requirements of British Standards for flushing out and cleaning perimeter floor drains, it is necessary to have perimeter floor drain joints, elbow bends and T-pieces that are securely fitted together and accurately aligned both axially and across inverts. The current methods of perimeter floor drain installation use a straight butt joint that is often held together with adhesive tape. These butt joints are easily disturbed both during their own installation and also during the subsequent floor laying and framed wall building operations that are carried out 
immediately on top of the perimeter floor drains by different tradespersons. At a corner joint in the perimeter floor drain the installers currently use a wood-saw to roughly mitre the corners of the perimeter floor drain and then attempt to wrap adhesive tape around the joint in less than favourable damp conditions; such joints are easily disturbed. In a similar manner, the T-pieces are formed by cutting out the side of a perimeter floor drain with a wood-saw and simply butt jointing an intersecting link drain connection, attempting to tape together the joint in the wet conditions. The end product inevitably results in a perimeter floor drain with joints that have moved and have thus produced obstructions to the flow of water around the perimeter floor drain. Subsequent attempts to flush out and clean the perimeter floor drain then result in water backing up around the perimeter floor drain leading to standing water and leaks into the occupied basement.

Some manufacturers and contractors have introduced rigid corner pieces and rigid T-pieces but these have brought their own problems. The rigid items are difficult to fit and align with the runs of the perimeter floor drains as most corners encountered in buildings are not exactly $90^{\circ}$ and most sumps cannot be directly accessed by a $90^{\circ} \mathrm{T}$-piece. Some adjustment of the $90^{\circ} \mathrm{T}$-piece is always necessary on site because the sump has to be installed so that as far as possible the water from the entire floor area being treated can find its way to the sump. The sump must be placed in an area like a door opening where it always remains accessible and the sump must be positioned so that a connection can be made to a nearby drain or so that the installed pump can be plumbed to a drainage point. More importantly, the use of rigid elbow bends and rigid T-pieces leads to the need for even more straight butt joints at each side of the installed fittings where they meet the straight lengths of perimeter floor drain that run around the floor perimeter. A solution is needed to insure that the inverts of a perimeter floor drain system when installed are kept level throughout and have no obstructions to impede water flow. The system must address the problems at joints, elbow bends and T-pieces were not only inverts must be in line but also the axial or longitudinal axis alignment of the perimeter floor drain and link drain must be maintained in order to ensure a secure fixing and also enable the flow of water along a channel that has no gradient. This will then ensure that the perimeter floor drain does not sit with standing water held continuously within the perimeter floor drain. When flushing out and cleaning is underway the water introduced can successfully make its way around the perimeter floor drain and flush any sediment into the sump, as required by the revised British Standards of BS8102: 2009. Therefore, this document discloses an accessible system having perimeter floor drains combined with new pivotally connected elbow bends that feature water deflectors and a new pivotally connected T-piece with internal deflector plate. The new bend and the new T-piece can be fitted to both one part and two part perimeter floor drains and so can be used with any manufacturers' perimeter floor drain to provide a secure joint with level inverts. 


\section{Detailed and diagrammatic description of the new system}

The system is described by reference to the accompanying drawings: Figure 1 is a line drawing of a typical perimeter floor drain that shows an end elevation of one part perimeter floor drain and two part snap together perimeter floor drain. Figure 1(a) shows a one part perimeter floor drain with an upstand (A), a perimeter floor drain can be installed with or without this upstand. The upstand is sometimes used against the inside wall of a building to hold the lower edge of a waterproofing structure in place and hence is not always needed. The one piece perimeter floor drain has holes (B) in the channel sidewall in order to collect water that has passed through the external building structure. Figure 1(b) shows a two part perimeter floor drain that consists of upper flat soffit section (C) and lower channel section (D). The two part perimeter floor drain may also feature an upstand (A) where needed and has the holes (B) to collect water ingress into channel section (D). The two separate parts, upper flat soffit section (C) and lower channel section (D) securely snap together as shown at (E).

Figure 2 is a plan view to show a typical basement installation of the new accessible system having perimeter floor drains combined with the new pivotally connected elbow bends and new T-piece. The external masonry structure of the building that serves to filter the water ingress as it enters the building is shown as (F). Inside the building the straight lengths of perimeter floor drain (as Figure 1) are shown as $(\mathrm{G})$ and the link drain $(\mathrm{H})$ transfers the water to the sump/pump (J) or gravity exit point. The pivotally connected T-piece with internal deflector $(\mathrm{K})$ transfers water from perimeter floor drain into the link drain $(\mathrm{H})$. The pivotally connected elbow bends (L) are situated at each internal corner of the building and can be adjusted to suit each corner to ensure axial alignment of perimeter floor drains. An access point or water jetting point $(\mathrm{N})$ can be used to introduce flushing water into the system which will then make its way around the perimeter floor drain as shown by arrows (M). The new pivotally connected elbow bends (L) and the new pivotally connected T-piece (K) will ensure that the inverts are level across every joint and that axial alignment of channels across joints is achieved. Hence without any obstructions the collected water will flow under gravity along the level channels to the T-piece $(\mathrm{K})$ where it will transfer into the link drain $(\mathrm{H})$ and into the sump $(\mathrm{J})$ for removal from the building [10].

Figure 3(a) shows the new pivotally connected elbow bend with internal deflector. The bend is pre-assembled as shown with two top flat soffit sections (P) which are mitred and then a pivotal connection is made across the mitred join using a connecting water deflector plate (R) and connectors (Q). The gap (W) between the two top section mitred edges and mitred channel sections (S) allows the two halves to rotate relative to each other so that the elbow bend can be fitted into building corners that are not exactly $90^{\circ}$. This is an important feature in maintaining both axial and invert alignment and it allows secure joints to be made between straight lengths of perimeter floor drain and the elbow bend fittings. The lower channel sections (S) extend out past the top sections (P) and are a feature of the new elbow bend as they are used to form a secure joint with the straight lengths of perimeter floor drain. If the two part perimeter floor drain 
(Figure 1(b)) is being used on an installation the straight channel of the perimeter floor drain is placed against the end of the extended elbow bend channel (S) and then the top section of the perimeter floor drain is snapped into place, spanning across the channel joint to create a secure staggered joint. There is no longer a straight butt joint that passes directly through both top and channel sections of the perimeter floor drain which is the major disadvantage associated with current rigid bends. If a one part perimeter floor drain is being used for the straight lengths of perimeter floor drain then the protruding channel section (S) will slide inside any manufacturers' one part perimeter floor drain channel currently available to form a secure joint. The pivotally connected elbow bend is universal and can therefore be used in installations of two part and one part perimeter floor drains and in both cases will provide a secure joint to the straight lengths of perimeter floor drain and the pivotal connection will ensure that soffits and inverts are kept at the same level across the bend to prevent obstructions to water flow [11].

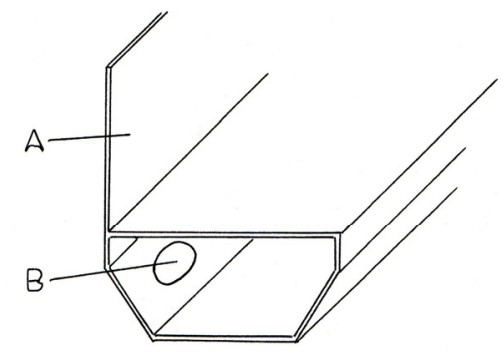

(a)
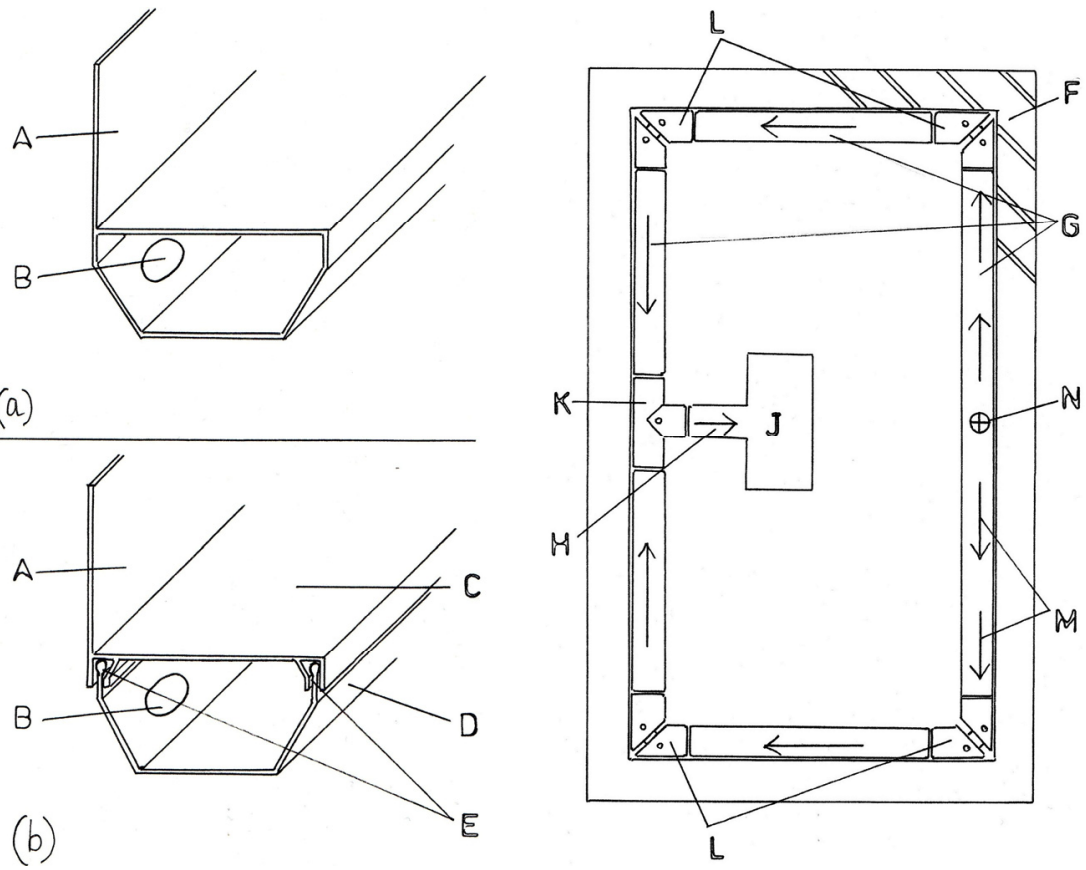

Figure 1: Sectional drawings of the Figure 2: Plan drawing of the perimeter floor drain. perimeter floor drain.

Figure 3(b) shows the pivotally connected T-piece with internal deflector plate. The top section (U) of a length of two part perimeter floor drain is pivotally connected $(\mathrm{Q})$ to the link drain top section $(\mathrm{V})$. This pivotal connection allows adjustment of the angle of intersection at the T-piece and ensures that on 
a construction site installation of the link drain is axially aligned into the T-piece in order to prevent obstructions to water flow and also achieve a secure joint. The link drain top section (V) is set under the top section (U) so that the invert in the link drain is lower than that of the perimeter floor drain to encourage water to flow from the level perimeter floor drain invert into the link drain invert. A length of two part lower channel section has the side wall cut away and is fixed into the top section (U), similarly a lower channel section is cut and fixed into the link drain top section (V). In both cases the channel sections are longer than their respective top sections and protrude out as shown (S). As previously described above for the elbow bend (see figure 3(a)) the protruding channels provide secure joints to both one part and two part perimeter floor drain straight lengths to ensure axial and invert alignment and hence no obstructions to flow. The lower channel section at the point of intersection must have the sidewall removed to allow water to pass into the link drain and removal of the sidewall weakens the construction of the T-piece and reduces the capacity of the flat top soffit section to handle floor loadings. A water deflector and support is internally fitted that spans between invert and flat soffit top section at the point of intersection. The support sits inside the T-piece in the channel section and serves to both support the weak flat top section and due to its shape also deflects water into the link drain passageway [12].

(a)

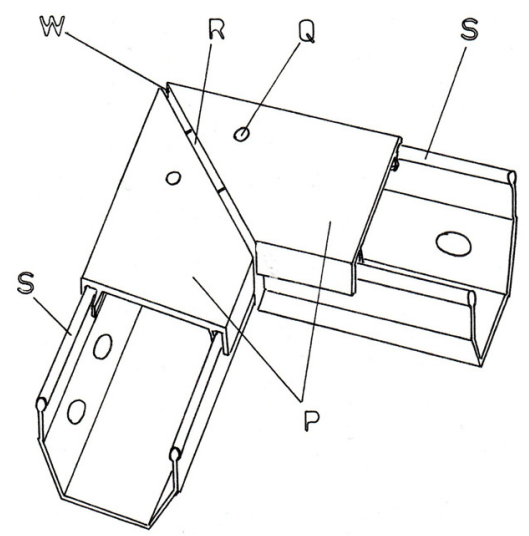

(b)

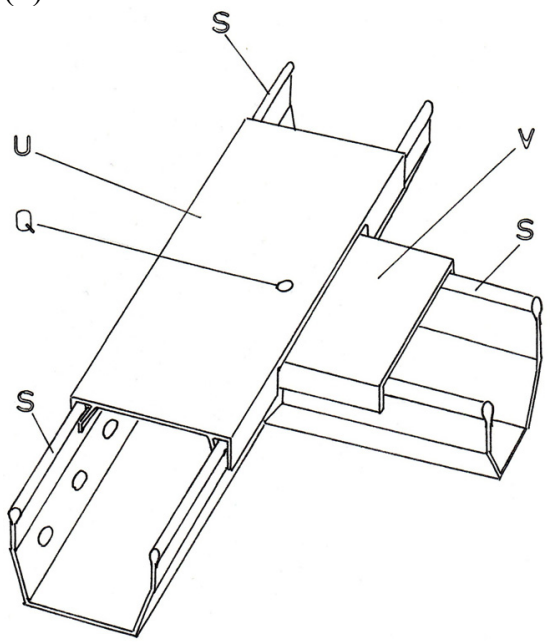

Figure 3: Sectional drawing to illustrate (a) the new pivotally connected elbow-bend with internal deflector and (b) the pivotally connected T-piece with internal deflector plate. 
Figure 4 is a plan view of perimeter floor drain, T-piece, link drain and sump chamber to show the accessibility provided by the new pivotally connected Tpiece with water deflector plate and support (b) and an existing standard T-piece in (a). The left hand side (a) shows perimeter floor drain A with a standard Tpiece $\mathrm{W}$ that joins the perimeter floor drain to the link drain G. Link drain G runs to the sump/pump chamber $\mathrm{H}$. The drain inspection camera or hose $\mathrm{R}$ can enter through the sump/pump chamber lid and be pushed along the link drain G. When $\mathrm{R}$ reaches the T-piece it cannot negotiate the corner into the perimeter floor drain and hits against the channel wall, there is no way to direct the camera or hose around the corner and along the perimeter floor drain. In Figure 4 the right hand side (b) the new T-piece has the internal water deflector plate and support $\mathrm{D}$ attached. The drain inspection camera or hose $\mathrm{R}$ can now pass around the corner into the length of the perimeter floor drain. By means of pushing $\mathrm{R}$ along different sides of the link drain both lengths of perimeter floor drain on either side of the T-piece can now be accessed. The internal water deflector plate and support $\mathrm{D}$ provides a constant radius for the bend in the inspection camera or hose and prevents kinking as they are fed through the T-piece $\mathrm{W}$ along the perimeter floor drain A.
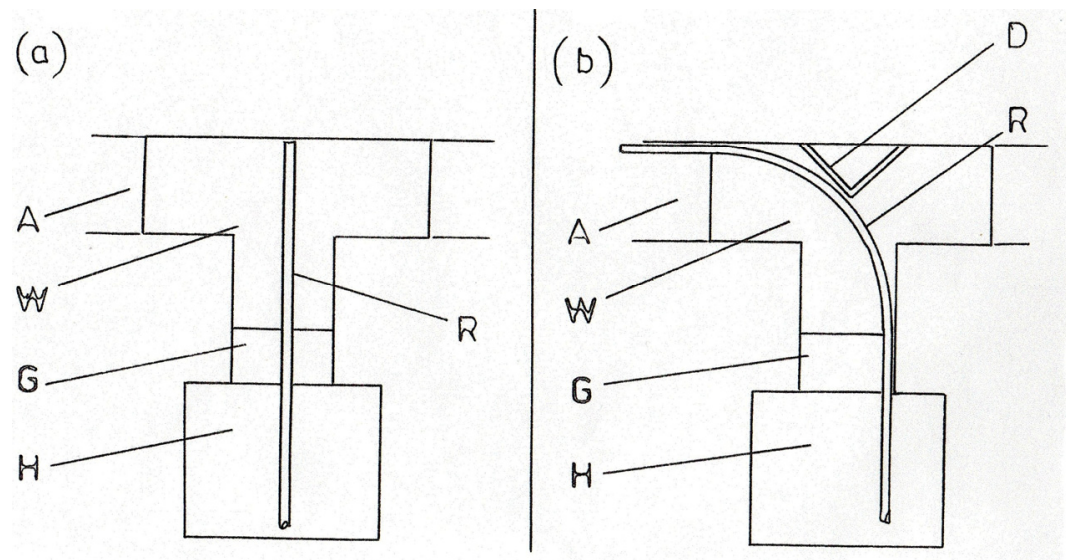

Figure 4: Plan views of the perimeter floor drain, T-piece, link drain and sump chamber to show the accessibility provided by the new pivotally connected T-piece with water deflector plate.

Figure 5(a) is a plan view to show water and/or sediment flowing into the sump/pump chamber. The flushing water has been introduced through jetting points set into the perimeter floor drain. In this plan the perimeter floor drain A is connected to the link drain $\mathrm{G}$ with a T-piece $\mathrm{W}$. The T-piece $\mathrm{W}$ has an internal support D attached. This plan shows the drainage system in use. The arrows $\mathrm{C}$ show the flow of water through the system. The perimeter floor drain collects water though pre-drilled holes in the channel sides, this water runs to the T-piece where it is passed into the link drain $\mathrm{G}$ and hence on to sump/pump chamber $\mathrm{H}$. 
The arrows $\mathrm{C}$ show flow of water and/or flow of sediment when the drainage system is being cleaned by flushing out. The support D stops water and/or sediment being washed back and forth across the end of the link drain and flows into the link drain G. Subsequently, sediment can be removed by way of the sump/pump chamber lid. As shown in Figure 4 one side of the new T-piece can be used to introduce a hose into the perimeter floor drain and the flushing water will then travel around the perimeter floor drain to carry sediment back to the new T-piece where the deflector plate will direct it into the link drain and then onto the sump for removal.

Figure 5(b) is a line drawing of the new T-piece to show the internal water deflector plate that also acts as a support for the T-piece soffit. For illustration purposes this drawing shows a rigid connection at the T-piece join, whereas in practice the new T-piece also features an adjustable joint and an invert level slightly lower in the link drain connection to aid water movement from perimeter floor drain to link drain and sump [12].

(a)

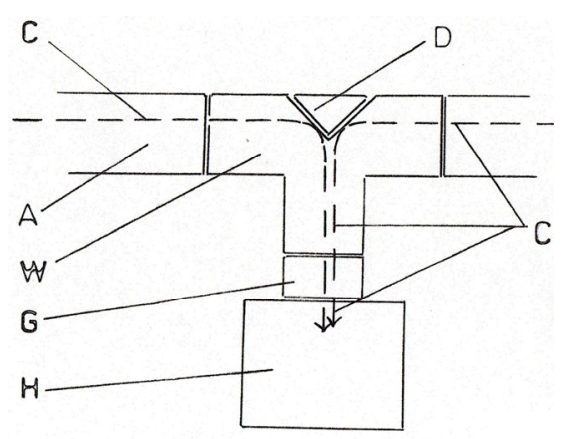

(b)

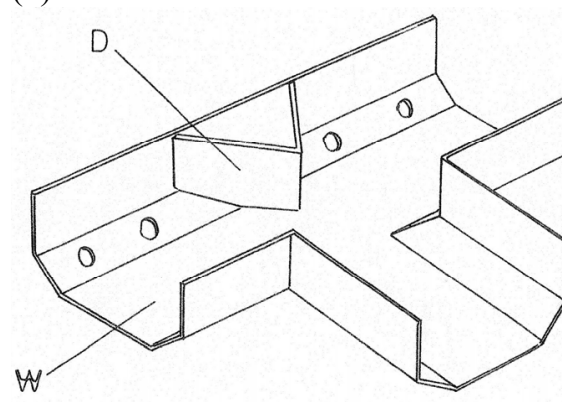

Figure 5: (a) Plan drawing to illustrate water and/or sediment flowing into the sump/pump chamber and (b) a sectional drawing of the new Tpiece to show the internal water deflector plate that also acts as a support for the T-piece soffit

\section{Discussion}

The products/system portrayed offers several advantages over existing approaches to the option of installing a drained cavity construction in a basement apartment. Pre-made elbow bends and T-piece make installation much easier and quicker during construction. The new T-piece with internal water deflector enables access into the perimeter floor drain system for inspection and effective flushing via the sump chamber. The pre-made bends can be fitted to the exact corner angle and then the secure joints hold the system together during assembly. The T-piece link drain connection can be accurately aligned to meet the sump location. The whole installation process needs less skill to complete, as the operatives no longer have to try and mitre odd shaped plastic mouldings with 
hand tools. With pre-made items the perimeter floor drain installation is simply snapped together with invert levels and axial alignment guaranteed (Figure 6). The deflector plates incorporated into corners and T-piece provide the accessibility as recommended by the revised British Standard BS8102 2009 for inspection and maintenance. The contractor can demonstrate on handover to the client that the system works and is now able to build in the accessibility to investigate any faults and also offer periodic maintenance contracts for the peace of mind of the client.
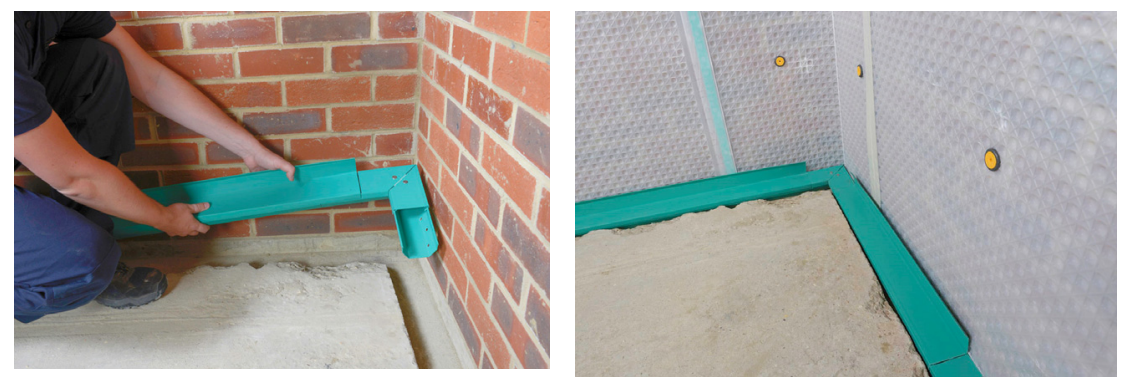

Figure 6: Photos of the newly designed, easy to fit, perimeter floor drain being installed by a semi-skilled professional in a basement apartment.

\section{Conclusions}

Shortage of housing is encouraging the conversion of building basements into habitable spaces. Mitigating the impact of below-ground living means there is a need to adapt and protect accommodation against water-ingress through the building envelope. Recommendations and guidance on the available approaches for dealing with the entry of water from surrounding ground into a structure below ground level include the use of a waterproofing barrier applied to the structure, creation of a structurally integral watertight construction or installation of a drained cavity construction. With the latter approach proving popular, new flood-resilient products, which provide means to access the inverts of perimeter floor drains and facilitate inspection and maintenance, are Patent Pending GB1117089.1, GB1102662.2, and GB1102661.4. These can demonstrate several practical advantages over those of existing designs and systems. Recognition is demonstrated by the commercial uptake by Safeguard Europe Ltd. and their installation in several hundred flood-risk basement apartments in the UK 


\section{References}

[1] Building Research Establishment, (2007) Good Building Guide 72: Basement Construction and Waterproofing. Part 1: Site Investigation and Preparation. Part 2 Construction, Safety, Insulation and Services. Amersham: IHS BRE Press.

[2] Construction Industry Research Information Association (1995) WaterResisting Basements- Report 140. London: CIRIA.

[3] Tovey, A. and Keyworth, B. (1998) Basements: Land Use and Energy Conservation - Evaluation with Market and Construction Survey. Crowthorne: British Cement Association.

[4] Basement Information Centre (2004) Basement Information Centre Approved Document - Basements for Dwellings. Camberley: BIC.

[5] Department of the Environment Transport and the Regions (1998) English House Condition Survey 1996. London: The Stationary Office.

[6] Wolcox, S. and Perry, J. (2013) UK Housing Review: 2013 Briefing Paper. Coventry: Chartered Institute of Housing.

[7] British Standards Institution (1990) BS8102:1990 Code of Practice for Protection of Structures against Water from the Ground. London: BSI.

[8] British Standards Institution (2009) BS8102:2009 Code of Practice for Protection of Below Ground Structures against Water from the Ground. London: BSI.

[9] Www.safeguardeurope.com/products/aquadrain.php

[10] Beddoes, D.W. (2011a) Cleanable Perimeter Drain System. Pat Pend. 117089.1.

[11] Beddoes, D.W. (2011b) Drain Deflector. Pat Pend. 1102662.2.

[12] Beddoes, D.W. (2011c) Perimeter Floor Drain T-Piece. Pat Pend. 1107397.0. 